\title{
Golgi phosphoprotein 2 in physiology and in diseases
}

\author{
Ha-Jeong Kim', Dandan Lv, Yan Zhang ${ }^{1}$, Tao Peng ${ }^{5^{*}}$ and Xiaojing Ma1,2,3,4*
}

\begin{abstract}
Golgi phosphoprotein 2 (GOLPH2, also termed GP73 and GOLM1) is a type II transmembrane protein residing in the cis and medial-Golgi cisternae. GOLPH2 is predominantly expressed in the epithelial cells of many human tissues. Under poorly defined circumstances, GOLPH2 can be cleaved and released to the extracellular space. Despite of its relatively "young age" since the first description in 2000, the physiological and pathological roles of GOLPH2 have been the subject that has attracted considerable amount of attention in recent years. Here, we review the history of GOLPH2's discovery and the multitude of studies by many groups around the world aimed at understanding its molecular, cellular, physiological, and pathogenic activities in various settings.
\end{abstract}

Keywords: GOLPH2, Hepatocellular carcinoma, Endosomal trafficking, Viral infection, Cell mediated immunity

\section{The GOLPH2 gene}

The $73 \mathrm{kDa}$ protein is coded by the gene GOLM1 located on human chromosome 9q21.33 (mouse chromosome 13) and was originally cloned by differential screening of a cDNA library derived from liver tissue of a patient with adult giant-cell hepatitis [1], a rare form of hepatitis with suspected viral etiology. GOLPH2 was also independently identified in "the secreted protein discovery initiative (SPDI), a large-scale effort to identify novel human secreted and transmembrane proteins using a biological signal sequence trap in yeast cells aided by computational tools [2]. The gene is conserved in chimpanzee, dog, cow, mouse, chicken, and zebrafish. The closest human homologue to GOLPH2 is the cancer susceptibility candidate gene 4 (CASC4) protein (Swiss-Prot Q6P4E1), a single-pass type II membrane protein that co-localizes with GOLPH2 (unpublished data of the authors), the increased expression level of which is associated with HER-2/neu proto-oncogene overexpression [3].

GOLPH2 genomic sequence predicts 11 exons and two splicing variants. The transcript variant 1 (NM_016548.3) is 3100 nt in length and contains exons 2 to 11 , while transcript variant 2 (NM_177937.2) is 3092nt in length

\footnotetext{
*Correspondence: peng_tao@gibh.ac.cn; xim2002@med.cornell.edu ${ }^{5}$ State Key Laboratory of Respiratory Disease, Guangzhou Institutes of Biomedicine and Health, Chinese Academy of Sciences, Guangzhou, China 'Department of Microbiology and Immunology, 1300 York Avenue, New York, NY 10065, USA

Full list of author information is available at the end of the article
}

and contains exons 1 , and 3 to 11 . Both variants encode the same open reading frame. The biological significance of these variants is not clear.

\section{Molecular and biochemical characteristics of GOLPH2}

Sequence analysis reveals that GOLPH2 contains a predicted transmembrane domain (TMD) at the N-terminal region, consistent with the observation that the protein can be found in the serum or cell culture supernatant, likely by secretion or by a shedding mechanism. Strikingly, it appears that the protein is entirely helical after the TMD, with two predicted continuous helical regions of 150 to 200 residues in length (Figure 1A). This striking helical nature of the protein may explain its observed resistance to proteases (unpublished data of the authors), because proteolysis requires a stretch of extended conformation such as $\beta$-strand conformation or random coil conformation. The apparent simplicity of the protein with regards to its secondary structure may also explain the heat resistance of the protein (unpublished data of the authors) because the protein may have an extraordinarily high denaturation temperature or may re-fold readily upon cooling. A search for sequence homology also revealed that a central region of the protein around residues 80-190 share low sequence homology (20-30\% identity) to several highly helical proteins, including 


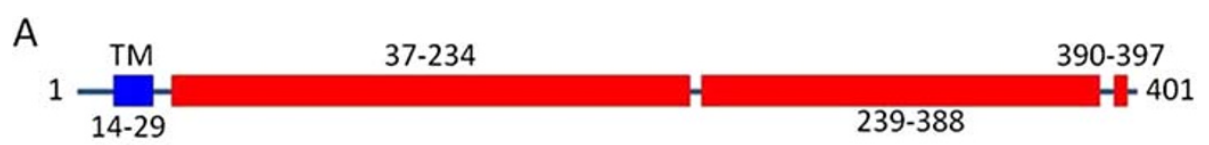

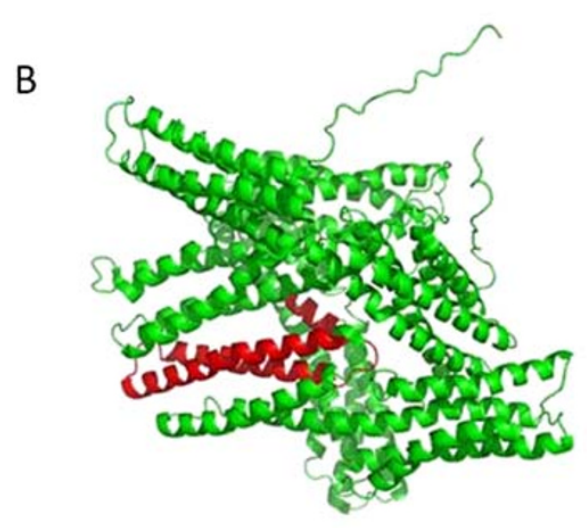

Vinculin

(region of homology shown in red)

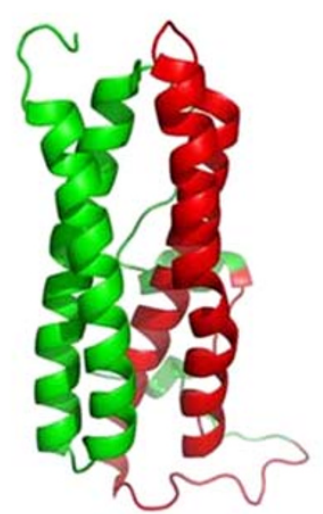

DNA-binding stress response protein (region of homology shown in red)

Figure 1 Structural features of GOLPH2. A. Predicted transmembrane (TM) and helical regions of the protein. Approximate residues ranges are labeled. B. Low but significant sequence homology to proteins with known structures.

Vinculin (PDBID 1ST6) and DNA-binding stress response protein $(2 \mathrm{C} 2 \mathrm{~F})$ (Figure $1 \mathrm{~B})$.

The amino acid residues 70-210 may contain a GCrich sequence DNA-binding factor-like protein domain although the significance of this observation is not clear. Further biochemical and structural characterization of GOLPH2 will help reveal its oligomerization state, stability and structural organization of the helices.

To understand how GOLPH2 gene expression is regulated, a 2,599-bp human GOLPH2 promoter fragment was cloned and characterized in epithelial cells including Hela, the HCC-derived HepG2, and breast cancer cell MCF7 [4]. Sequence analysis indicates that GOLPH2 core promoter does not contain the canonical TATA element. Deletion analyses revealed three important domains: a repressive region, a positive regulatory region and a core promoter region. Furthermore, adenoviral early region $1 \mathrm{~A}(\mathrm{E} 1 \mathrm{~A})$ was able to activate the GOLPH2 promoter, consistent with the original description of GOLPH2's induction by viral infection [5]. A GC-box motif located at -89 to -83 in the core GOLPH2 promoter region partly mediated E1A transactivation [4].

\section{Trafficking of GOLPH2}

Under steady-state conditions GOLPH2 is an integral membrane protein of the cis and medial-Golgi. However, similarly to the structurally related protein GPP130, it cycles out of the cis Golgi to endosomes and the cell surface [6]. There is evidence that the endosomal trafficking of GOLPH2 allows for proprotein convertase furin- mediated cleavage, resulting in its release into the extracellular space, and provides a molecular explanation for its presence as a serum biomarker for HCC [7]. The structural determinants for Golgi localization were investigated using a panel of GOLPH2 truncation mutants [8]. The Golgi localization of GOLPH2 was not affected by the deletion of the C-terminal part of the protein. A truncated mutant containing the $\mathrm{N}$-terminal portion (the cytoplasmic tail and TMD) localized to the Golgi. Sequential deletion analysis of the $\mathrm{N}$-terminus indicated that the TMD with a positively charged residue in the cytoplasmic N-terminal tail were sufficient to support Golgi localization. It was also shown that both endogenous and secreted GOLPH2 exist as a disulfide-bonded dimer, and the coiled-coil domain was sufficient for dimerization [8].

To note, it has been speculated from the beginning that GOLPH2 might be important for protein transportation; however, no direct evidence has been reported yet demonstrating its role in this process.

\section{GOLPH2 in development}

GOLPH2's physiological importance was inferred by an early study showing that transgenic mice expressing a C-terminally truncated GOLPH2 exhibit decreased survival and hepato-renal pathology with strong inflammatory cell infiltrates [9]. This renal pathology is partially mimicked in the knockout mice for the lipoprotein clusterin (CLU) [10], the secretory form of which (sCLU) has been shown by us to interact with secretory GOLPH2 through the latter's C-terminus [11]. 
GOLPH2 is highly conserved among vertebrates, suggesting that it performs a conserved biological function. Indeed, studies revealed impressive levels of similarities between human and Xenopus GOLPH2s. Both proteins are localized in golgi and forms dimer in a similar manner. More important, both proteins are highly expressed in epithelial cells, suggesting mechanisms of expression regulation. In an effort to understand the physiological function of GOLPH2, the developmental role of GOLPH2 in the Xenopus model was characterized. Xenopus golph2 is expressed in the pronephros during early development. The morpholino-mediated knockdown of golph2 results in edema formation. Additionally, Nephrin expression is enhanced in the glomus, and the expression of pronephric marker genes, such as atp1b1, $C l C-K, N K C C 2$, and $N B C 1$, is diminished in the tubules and duct. The expression of WT1 is increased in the glomus and expanded laterally in the pronephric region, which may promote glomus formation and inhibit pronephric tubule differentiation [12]. Continued utilization of a relatively simple but well-defined model system such as Xenopus laevis will lead to a better understanding of the biological functions, pathogenesis and other important physiological properties of GOLPH2.

\section{GOLPH2 in liver diseases}

Clinical studies first uncovered high levels of GOLPH2 in the sera of patients with liver disease, particularly hepatocellular carcinoma (HCC) [13-15]. Compared with $\alpha$ fetoprotein (AFP), the most commonly used serum marker for over four decades, GOLPH2 serum levels appear to be more sensitive for early HCC $[14,16]$. Further, GOLPH2 is hyperfucosylated in HCC, and its hyperfucosylated fraction in serum is an even better disease marker [13]. The most profound elevation of serum levels of GOLPH2 has been detected in patients who have developed HCC on the background of infections by HCV genotype $1 \mathrm{~b}$ and HBV [17]. A recent Chinese study was conducted with systematic review of related studies, sensitivity, specificity and other measures about the accuracy of serum GOLPH2 and AFP in the diagnosis of HCC using random-effects models. The results of this study indicate that serum GOLPH2 has a comparable accuracy to AFP for the diagnosis of HCC, while the value of serum GOLPH2 in combination with AFP for HCC detection warrants further investigations [18].

In a study aimed to investigate the expression of GOLPH2 and its correlation with clinical parameters, significant overexpression of GOLPH2 at either proteinor mRNA-levels or both were fund to be associated with aggressive behavior of HCC, but not overall patient survival [19]. This observation suggests that GOLPH2 is not merely a marker of $\mathrm{HCC}$ progression but it may have HCC-promoting activities.

\section{GOLPH2 in other diseases}

GOLPH2 has been described as an excellent ancillary tissue biomarker for the diagnosis of prostate cancer [20-22]. One study revealed significantly elevated GOLPH2 expression in lung adenocarcinoma tissues [23]. Interestingly, the levels of soluble GOLPH2 (sGOLPH2) were about $30 \%$ higher in lung cancer patients compared with healthy individuals [23]. GOLPH2 is consistently overexpressed in seminomas compared with matching nonneoplastic tissues with statistically high significance [24]. GOLPH2 is also highly expressed in the intertubular Leydig cells as well as in Leydig cell tumors [24]. High GOLPH2 expression has been observed in normal renal tubules and in almost half of renal cell carcinomas (RCC) with a statistically significant predominance in the papillary and chromophobe histological subtypes [25].

A case-control Genome-wide association study (GWAS) with replication in Canada and the United Kingdom shows that unadjusted, single nucleotide polymorphism (SNP) rs4420638 within APOC1 is strongly associated with Alzheimer's disease (AD) due entirely to linkage disequilibrium with $A P O E$. By multivariable adjusted analyses, 3 SNPs within the top 120 by $P$ value in the logistic analysis and 1 in the Cox analysis of the Canadian data set provides additional evidence for association at $P<0.05$ within the United Kingdom Medical Research Council data set: rs7019241 (GOLPH2), rs10868366 (GOLPH2), rs9886784 (chromosome 9), and rs10519262 (intergenic between ATP8B4 and SLC27A2) [26]. In a study of the Han Chinese population, rs10868366 and rs7019241 in GOLPH2 were found to be in strong linkage disequilibrium. Furthermore, the rs10868366 T/rs7019241 $\mathrm{T}$ alleles form a relative protective factor whereas the rs10868366 G/rs7019241 C alleles constitute a relative risk factor [27]. Another Chinese study found that the ApoE€4-associated risk of $\mathrm{AD}$ increased approximately two-fold if the GOLPH2-T allele of rs7019241 was also present, suggesting that GOLPH2 modifies the ApoE€4-associated risk of AD [28].

\section{GOLPH2's potential activities in the immune system}

One of the traditional immunological paradigms is that B-cell and T-cell interactions are a one-way phenomenon of T-cell help to induce the terminal differentiation of B cells to produce antibodies $[29,30]$. However, recently emerging evidence indicates that $\mathrm{B}$ cells may have strong regulatory effects on $\mathrm{T}$ cell-mediated immune responses [31-33]. The mechanisms are not well understood. A proteomics-based approach was adopted to identify protein molecules potentially important for this much underexplored but important pathway of immunoregulation (unpublished data of the authors). Initial screening identified a secreted activity by pathogen- 
activated primary human and mouse B lymphocytes, and by many types of neoplastic B cells spontaneously. This novel activity strongly suppresses $\mathrm{T}$ cell responses indirectly by modulating dendritic cell (DC) properties through a selective inhibition of the production of Interleukin-12 (IL-12), a heterodimeric cytokine essential for $\mathrm{T}_{\mathrm{H}} 1$-mediated immunity against intracellular infection and malignant growth. By a combination of biochemical and mass spectrometric analyses, it was further determined that the major activity of this factor was in fact GOLPH2. The "co-incidental" convergence of the autonomously carried out immunological investigations by us and clinical studies by others on GOLPH2 strongly hints at the potential importance of this intriguing molecule. It is tempting to speculate that the sGOLPH2 by HCC may have a pathological role, which is to inhibit IL-12 production by $\mathrm{DCs}$, thwarting $\mathrm{T}$ cell responses against malignant development. GOLPH2 may also have immuneindependent activities on HCC growth and/or metastasis in vivo.

The $\mathrm{T}_{\mathrm{H}} 1 / \mathrm{T}_{\mathrm{H}} 2$ balance is impaired in many disorders, including infectious and autoimmune diseases and malignancies. In AIDS, for example, there is strong evidence that as the disease progresses hyperactivation of $B$ lymphocytes and cytokine dysregulation occur, and the overproduction of type- 2 cytokines (IL-4, IL-13, etc.) promotes $\mathrm{T}_{\mathrm{H}} 2$ immune responses associated with a permissive environment for the survival and persistence of the virus, accompanied by impaired production of type1 cytokines (IL-12, IFN- $\gamma$ ) and diminished cell mediated immunity (CMI), which is an indispensable and critical mechanism to eliminate HIV infected cells and control the spread of infection [34]. Consistent with these observations, in vivo treatment with recombinant IL-12 protects mice from immune abnormalities observed during murine acquired immunodeficiency syndrome (MAIDS) [35]. IL-12 also enhanced the cellular immune response in vivo against human HIV-1 env antigen in a DNA prime/vaccinia virus boost vaccine regimen [36].

It is therefore further postulated that hyperactive $B$ cells inhibit IL-12 gene expression in DCs by producing the extracellular GOLPH2, thereby dampening DC/IL12-driven CMI against persistent and chronic intracellular infections in which B cell activation is dysregulated, such as in HIV/AIDS.

\section{Conclusions}

Given its strong association with a number of important diseases, GOLPH2 is an intriguing molecule that deserves fruther exploration. Future efforts towards understanding its roles and mechanisms in physiological and pathogenic settings can be direted but not limited to the following aspects: (1) to delineate its potential role in mammalian development and cellular differentiation;
(2) to further study its role in viral infections of epithelial cells; (3) to differentiate the roles of the intracellular vs the extracellular GOLPH2; (4) to identify its putative cellular receptor through which the sGOLPH2 induces intracellular signaling; (5) to investigate the immunological and non-immune roles of sGOLPH2 in HCC growth and metastasis in immunocompetent and xenographic mouse models of HCC, respectively; (6) to investigate the molecular mechanism of $\mathrm{B}$ cell-mediated evasion of CMI via inhibition of IL-12 synthesis in DCs by sGOLPH2.

\section{Competing interests}

The author(s) declare that they have no competing interests.

\section{Authors' contributions}

HK identified GOLPH2 from B lymphocytes and characterized many of its in vitro activities in macrophages and dendritic cells. DL carried out the IL-12 p35 reporter assays. YZ performed some of the GOLPH2 expressionknockdown studies.TP did most of the biochemical characterization of GOLPH2 as well as the developmental work. XM was responsible for the overall direction of the project and for the writing of this manuscript. All authors read and approved the final manuscript.

\section{Author details}

'Department of Microbiology and Immunology, 1300 York Avenue, New York, NY 10065, USA. ${ }^{2}$ Department of Pediatrics, Weill Cornell Medical College, 1300 York Avenue, New York, NY 10065, USA. ${ }^{3}$ Graduate Program in Immunology and Microbial Pathogenesis, Weill Graduate School of Medical Sciences, Cornell University, 1300 York Avenue, New York, NY 10065, USA. ${ }^{4}$ School of Life Science and Biotechnology, Shanghai Jiao Tong University, Shanghai 200240, China. ${ }^{5}$ State Key Laboratory of Respiratory Disease, Guangzhou Institutes of Biomedicine and Health, Chinese Academy of Sciences, Guangzhou, China.

Received: 1 June 2012 Accepted: 18 July 2012

Published: 10 September 2012

\section{References}

1. Kladney RD, Bulla GA, Guo L, Mason AL, Tollefson AE, Simon DJ, Koutoubi Z, Fimmel CJ: GP73, a novel Golgi-localized protein upregulated by viral infection. Gene 2000, 249:53-65.

2. Clark HF, Gurney AL, Abaya E, Baker K, Baldwin D, Brush J, Chen J, Chow B, Chui C, Crowley C, Currell B, Deuel B, Dowd P, Eaton D, Foster J, Grimaldi C, Gu Q, Hass PE, Heldens S, Huang A, Kim HS, Klimowski L, Jin Y, Johnson S, Lee J, Lewis L, Liao D, Mark M, Robbie E, Sanchez C, et al: The secreted protein discovery initiative (SPDI), a large-scale effort to identify novel human secreted and transmembrane proteins: a bioinformatics assessment. Genome Res 2003, 13:2265-2270.

3. Oh JJ, Grosshans DR, Wong SG, Slamon DJ: Identification of differentially expressed genes associated with HER-2/neu overexpression in human breast cancer cells. Nucleic Acids Res 1999, 27:4008-4017.

4. Gong Y, Long Q, Xie H, Zhang T, Peng T: Cloning and characterization of human Golgi phosphoprotein 2 gene (GOLPH2/GP73/GOLM1) promoter. Biochem Biophys Res Commun 2012, 421:713-720.

5. Kladney RD, Tollefson AE, Wold WS, Fimmel CJ: Upregulation of the Golgi protein GP73 by adenovirus infection requires the E1A CtBP interaction domain. Virology 2002, 301:236-246.

6. Puri S, Bachert C, Fimmel CJ, Linstedt AD: Cycling of early Golgi proteins via the cell surface and endosomes upon lumenal $\mathrm{pH}$ disruption. Traffic 2002, 3:641-653.

7. Bachert C, Fimmel C, Linstedt AD: Endosomal trafficking and proprotein convertase cleavage of cis Golgi protein GP73 produces marker for hepatocellular carcinoma. Traffic 2007, 8:1415-1423.

8. Hu L, Li L, Xie H, Gu Y, Peng T: The Golgi localization of GOLPH2 (GP73/ GOLM1) is determined by the transmembrane and cytoplamic sequences. PLoS One 2011, 6:e28207. 
9. Wright LM, Yong S, Picken MM, Rockey D, Fimmel CJ: Decreased survival and hepato-renal pathology in mice with C-terminally truncated GP73 (GOLPH2). Int J Clin Exp Pathol 2009, 2:34-47.

10. Ghiggeri GM, Bruschi M, Candiano G, Rastaldi MP, Scolari F, Passerini P, Musante L, Pertica N, Caridi G, Ferrario F, Perfumo F, Ponticelli C: Depletion of clusterin in renal diseases causing nephrotic syndrome. Kidney Int 2002, 62:2184-2194.

11. Zhou Y, Li L, Hu L, Peng T: Golgi phosphoprotein 2 (GOLPH2/GP73/ GOLM1) interacts with secretory clusterin. Mol Biol Rep 2011, 38:1457-1462.

12. Li L, Wen L, Gong Y, Mei G, Liu J, Chen Y, Peng T: Xenopus as a Model System for the Study of GOLPH2/GP73 Function: Xenopus golph2 is Required for Pronephros Development. PLoS One 2012, 7:e38939.

13. Block TM, Comunale MA, Lowman M, Steel LF, Romano PR, Fimmel C, Tennant BC, London WT, Evans AA, Blumberg BS, Dwek RA, Mattu TS, Mehta AS: Use of targeted glycoproteomics to identify serum glycoproteins that correlate with liver cancer in woodchucks and humans. ProcNat/Acad SciU S A 2005, 102:779-784.

14. Marrero JA, Romano PR, Nikolaeva O, Steel L, Mehta A, Fimmel CJ, Comunale MA, D'Amelio A, Lok AS, Block TM: GP73, a resident Golgi glycoprotein, is a novel serum marker for hepatocellular carcinoma. J Hepatol 2005, 43:1007-1012.

15. Mao $Y$, Yang $H, X u H$, Lu X, Sang $X$, Du S, Zhao H, Chen W, Xu Y, Chi T, Yang Z, Cai J, Li H, Chen J, Zhong S, Mohanti SR, Lopez-Soler R, Millis JM, Huang J, Zhang H: Golgi protein $73(\mathrm{GOLPH} 2)$ is a valuable serum marker for hepatocellular carcinoma. Gut 2010, 59:1687-1693.

16. Li X, Wu K, Fan D: Serum golgi phosphoprotein 2 level: a better marker than alpha-fetoprotein for diagnosing early hepatocellular carcinoma. Hepatology 2009, 50:1682.

17. Riener MO, Stenner F, Liewen H, Soll C, Breitenstein S, Pestalozzi BC, Samaras P, Probst-Hensch N, Hellerbrand C, Mullhaupt B, Clavien PA, Bahra M, Neuhaus P, Wild P, Fritzsche F, Moch H, Jochum W, Kristiansen G: Golgi phosphoprotein 2 (GOLPH2) expression in liver tumors and its value as a serum marker in hepatocellular carcinomas. Hepatology 2009, 49:1602-1609.

18. Zhou Y, Yin X, Ying J, Zhang B: Golgi protein 73 versus alpha-fetoprotein as a biomarker for hepatocellular carcinoma: a diagnostic meta-analysis. BMC Cancer 2012, 12:17.

19. Sun Y, Yang H, Mao Y, Xu H, Zhang J, Li G, Lu X, Sang X, Zhao H, Zhong S, Huang J, Zhang $H$ : Increased Golgi protein 73 expression in hepatocellular carcinoma tissue correlates with tumor aggression but not survival. J Gastroenterol Hepatol 2011, 26:1207-1212.

20. Kristiansen G, Fritzsche FR, Wassermann K, Jager C, Tolls A, Lein M, Stephan C, Jung K, Pilarsky C, Dietel M, Moch H: GOLPH2 protein expression as a novel tissue biomarker for prostate cancer: implications for tissue-based diagnostics. Br J Cancer 2008, 99:939-948.

21. Wei S, Dunn TA, Isaacs WB, De Marzo AM, Luo J: GOLPH2 and MYO6: putative prostate cancer markers localized to the Golgi apparatus. Prostate 2008, 68:1387-1395.

22. Laxman B, Morris DS, Yu J, Siddiqui J, Cao J, Mehra R, Lonigro RJ, Tsodikov A, Wei JT, Tomlins SA, Chinnaiyan AM: A first-generation multiplex biomarker analysis of urine for the early detection of prostate cancer. Cancer Res 2008, 68:645-649.

23. Zhang F, Gu Y, Li X, Wang W, He J, Peng T: Up-regulated Golgi phosphoprotein 2 (GOLPH2) expression in lung adenocarcinoma tissue. Clin Biochem 2010, 43:983-991.

24. Fritzsche FR, Kristiansen G, Riener MO, Dietel M, Oelrich B: GOLPH2 expression may serve as diagnostic marker in seminomas. BMC Urol 2010, 10:4.

25. Fritzsche FR, Riener MO, Dietel M, Moch H, Jung K, Kristiansen G: GOLPH2 expression in renal cell cancer. BMC Urol 2008, 8:15.

26. Li H, Wetten S, Li L, St Jean PL, Upmanyu R, Surh L, Hosford D, Barnes MR, Briley JD, Borrie M, Coletta N, Delisle R, Dhalla D, Ehm MG, Feldman HH, Fornazzari L, Gauthier S, Goodgame N, Guzman D, Hammond S, Hollingworth P, Hsiung GY, Johnson J, Kelly DD, Keren R, Kertesz A, King KS, Lovestone S, Loy-English I, Matthews PM, et al: Candidate singlenucleotide polymorphisms from a genomewide association study of Alzheimer disease. Arch Neurol 2008, 65:45-53.

27. Yuan Q, Chu C, Jia J: Association studies of 19 candidate SNPs with sporadic Alzheimer's disease in the North Chinese Han population. Neurol Sci 2011, Dec 14. [Epub ahead of print].
28. Lin $K$, Tang M, Han H, Guo Y, Lin Y, Ma C: Association between the polymorphisms of CALHM1 and GOLPH2 genes and Alzheimer's disease. Psychiatr Genet 2010, 20:190.

29. Liu YJ, Joshua DE, Williams GT, Smith CA, Gordon J, MacLennan IC: Mechanism of antigen-driven selection in germinal centres. Nature 1989, 342:929-931.

30. Rousset F, Garcia E, Banchereau J: Cytokine-induced proliferation and immunoglobulin production of human B lymphocytes triggered through their CD40 antigen. J Exp Med 1991, 173:705-710.

31. Bennett SR, Carbone FR, Toy T, Miller JF, Heath WR: B cells directly tolerize CD8(+) T cells. J Exp Med 1998, 188:1977-1983.

32. Eynon EE, Parker DC: Small B cells as antigen-presenting cells in the induction of tolerance to soluble protein antigens. J Exp Med 1992, 175:131-138.

33. Fuchs EJ, Matzinger P: B cells turn off virgin but not memory T cells. Science 1992, 258:1156-1159.

34. Villinger $F$, Ansari AA: Role of IL-12 in HIV infection and vaccine. Eur Cytokine Netw 2010, 21:215-218.

35. Gazzinelli RT, Giese NA, Morse HC 3rd: In vivo treatment with interleukin 12 protects mice from immune abnormalities observed during murine acquired immunodeficiency syndrome (MAIDS). J Exp Med 1994, 180:2199-2208.

36. Gherardi MM, Ramirez JC, Esteban M: Interleukin-12 (IL-12) enhancement of the cellular immune response against human immunodeficiency virus type 1 env antigen in a DNA prime/vaccinia virus boost vaccine regimen is time and dose dependent: suppressive effects of IL-12 boost are mediated by nitric oxide. J Virol 2000, 74:6278-6286.

doi:10.1186/2045-3701-2-31

Cite this article as: Kim et al:: Golgi phosphoprotein 2 in physiology and in diseases. Cell \& Bioscience 2012 2:31.

\section{Submit your next manuscript to BioMed Central and take full advantage of:}

- Convenient online submission

- Thorough peer review

- No space constraints or color figure charges

- Immediate publication on acceptance

- Inclusion in PubMed, CAS, Scopus and Google Scholar

- Research which is freely available for redistribution

Submit your manuscript at www.biomedcentral.com/submit
C Biomed Central 